\title{
An analysis of false positive reactions occurring with the Captia Syph G EIA
}

\author{
J Ross, A Moyes, H Young, A McMillan
}

\begin{abstract}
Aim-The Captia Syph G enzyme immuno assay (EAI) offers the potential for the rapid automated detection of syphilis antibodies. This study was designed to assess the role of other sexually transmitted diseases (STDs) in producing false positive reactions in the Captia Syph G EIA. The role of rheumatoid factor (RF) as a potential source of false positives was also analysed.

Methods-Patients who attended a genitourinary medicine (GUM) department and gave a false positive reaction with the EIA between 1988 and 1990 were compared with women undergoing antenatal testing and with the control clinic population (EIA negative) over the same time period. The incidence of sexually transmitted disease (STD) in the clinic population and the false positive reactors was measured in relation to gonorrhoea, chlamydia, genital warts, candidiasis, "other conditions not requiring treatment" and "other conditions requiring treatment." Male:female sex ratios were also compared. Ninety two RF positive sera were analysed with the EIA.

Results-The rate of false positive reactions did not differ with respect to the diagnosis within the GUM clinic population. The antenatal group of women, however, had a lower incidence of false positive reactions than the GUM clinic group. No RF positive sera were positive on Captia Syph G EIA testing.

Conclusions-There is no cross reaction between Captia Syph G EIA and any specific STD or with RF positive sera. The lower incidence of false positive reactions in antenatal women is unexplained but may be related to physiological changes associated with pregnancy.
\end{abstract}

Department of Genitourinary Medicine, Edinburgh Royal Infirmary

J Ross, A McMillan

Department of Medical Microbiology, University of Ediburgh

A Moyes, H Young
Introduction

The recent introduction of the Captia Enzyme Immunoassay (Captia Syph G) to detect immunoglobulin $\mathrm{G}$ (IgG) antibodies against Treponema pallidum presents an opportunity for automated processing and reporting for large numbers of specimens. ${ }^{1-3}$ This EIa test with an overall sensitivity of over $98 \%$ and specificity of over $99 \%{ }^{23}$ is comparable in performance with the traditional combination of VDRL (Venereal Disease Research Laboratory) and TPHA (Treponema pallidum Haemagglutination Assay) tests even in primary syphilis. ${ }^{1}$ False negatives in the EIA were associated specifically with primary infection where the sensitivity was $82 \% .^{2}$ False positive reactions were not associated with conventional Biological False Positive Reactors. ${ }^{3}$

The incidence of syphilis in general, and the primary stage in particular, is low in the United Kingdom, however, and the occurrence of false positive reactions, albeit at a low level, decreases the positive predictive value of a positive test. The factors responsible for these erroneous reactions with the EIA are not known.

The antigen in the Captia Syph G EIA is a sonicate of $T$. pallidum (Nichols strain) coated onto microtitration wells. Unlike other $T$. pallidum antigen tests such as the Fluorescent Treponemal Antibody Absorbed (FTA-ABS) test ${ }^{4}$ and the TPHA ${ }^{5}$ that comprise an absorbtion stage to neutralise group treponemal antibody, the EIA involves no such absorbtion and relies on serum dilution ( 1 in 20) to overcome interference from group treponemal antibody.

Because of the lack of an absorption stage it is possible that more false positive reactions might occur in patients attending an STD clinic; this could result from damage to the mucosal epithelium encouraging the growth of commensal treponemes. Excessive growth of such treponemes in genital lesions may give rise to false positive FTA-ABS reactions if the group reactive antibody is not completely neutralised. ${ }^{\circ}$ In view of this we compared the rate of false positive EIA reactions in patients attending an STD clinic with that for women attending an antenatal clinic. A number of sera positive for rheumatoid factor (RF) were also tested in order to exclude this as a cause of false positive reactions. 
Table 1 STD prevalence in EIA negative and EIA false-positive clinic population

\begin{tabular}{|c|c|c|c|c|}
\hline & \multicolumn{2}{|c|}{$\begin{array}{l}\text { Total } \\
\text { STD clinic population }\end{array}$} & \multicolumn{2}{|c|}{$\begin{array}{l}\text { False positive EIA } \\
\text { STD clinic population }\end{array}$} \\
\hline & \multicolumn{2}{|c|}{$n=12842$} & \multicolumn{2}{|l|}{$n=197$} \\
\hline & Male & Female & Male & Female \\
\hline $\begin{array}{l}\text { Gonorrhoea } \\
\text { Chlamydial infection } \\
\text { Genital warts } \\
\text { Candidiasis } \\
\text { Other (untreated) } \\
\text { Other (treated) } \\
\text { Pregnancy }\end{array}$ & $\begin{array}{r}381 \\
2309 \\
2615 \\
88 \\
2523 \\
2949\end{array}$ & $\begin{array}{rl} & 243 \\
& 606 \\
1 & 893 \\
1 & 270 \\
1 & 544 \\
2 & 529 \\
10 & 314\end{array}$ & $\begin{array}{c}5(1 \cdot 3 \%) \\
31(1 \cdot 3 \%) \\
31(1 \cdot 2 \%) \\
0(0 \%) \\
37(1 \cdot 5 \%) \\
38(1 \cdot 3 \%)\end{array}$ & $\begin{array}{r}2(0.8 \%) \\
8(1.3 \%) \\
27(1.4 \%) \\
14(1.1 \%) \\
22(1.4 \%) \\
36(1.4 \%) \\
82(0.8 \%)\end{array}$ \\
\hline
\end{tabular}

Figures in parenthesis represent the percentage of total incidence for each condition.

\section{Methods}

All patients who attended the Department of Genitourinary Medicine, Edinburgh Royal Infirmary between January 1988 and December 1990 and were screened for syphilis by the Captia Syph G (Mercia Diagnostics UK) EIA were included in the study. All sera were heat inactivated at $56^{\circ} \mathrm{C}$ for 30 minutes prior to serological testing. Sera giving an antibody index ${ }^{3}$ greater than or equal to 0.9 were repeat tested once by the EIA and were examined by the VDRL, TPHA and FTA-ABS and an EIA for specific antitreponemal IgM (Captia Syph $M$ ). Whenever requested, sera from patients at high risk for syphilis, particularly early primary syphilis were examined by all of the above tests. A false positive EIA was taken as an antibody index of greater than or equal to 0.9 which persisted on one repeat test but was not supported by confirmatory treponemal tests and signs or symptoms of treponemal infection.

Comparison was made between the patients with false positive reactions and the overall clinic population with regard to the prevalence of gonorrhoea, chlamydial infection, genital warts, candidiasis, "other conditions not requiring treatment" and "other conditions which required treatment." The last group included patients who had infected partners and received therapy on an epidemiological basis. Patients who had more than one diagnosis were counted in each diagnostic group separately. The male to female sex ratio (M:F) was calculated for each group.

The overall false positive rate in the clinic population was also compared with that of pregnant women screened for syphilis at the Simpson Memorial Maternity Pavilion, Edinburgh between 1988 and 1990.

Sera found positive on screening with the Serascan Rheumatoid Arthritis Latex test (Hycor) were also tested with the Captia Syph G EIA.

Statistical analysis was performed using the chi square test on the Minitab PC statistics package.

\section{Results}

Over the 3 year period 12842 new patients were seen in the Department of Genitourinary Medicine. False positive reactions occurred in $197(1.5 \%)$ compared with 117 confirmed positive tests for syphilis, giving a positive predictive value of $37 \%$. The $M: F$ ratio was $124: 73(1.7: 1)$ in the false positive group compared with $7593: 5249(1.4: 1)$ in the STD clinic population, which is not statistically significant. The prevalence of sexually transmitted diseases in the clinic population and in those giving false positive reactions are shown in table 1 . The only statistically significant difference between the groups is a lower incidence of genital warts in those with false positive EIA $(p=0.02)$.

Of patients who had positive EIA results 182 $(1.4 \%)$ became negative on repeat testing.

Antenatal patients $\left(\begin{array}{ll}10 & 314\end{array}\right)$ were tested with 82 false positives $(0.8 \%)$. This level is significantly lower than the STD clinic population $(\mathrm{p}<0.01)$. Only three $(1.5 \%)$ of the 197 GUM patients and $1(1.2 \%)$ of the antenatal patients with false positive IgG reactions also gave a false positive IgM test.

The RF titres of the RF positive sera are shown in table 2. All 92 of the RF positive sera were negative on testing with the Captia Syph G EIA.

\section{Discussion}

Despite a specificity of greater than $99 \%$ a positive

Table 2 RF titres in RF positive sera

\begin{tabular}{lll}
\hline & $R F$ titre $(I U / \mathrm{ml})$ & No of patients \\
\hline 20 & 38 \\
40 & 23 \\
80 & 15 \\
160 & 6 \\
& 320 & 4 \\
640 & 3 \\
& 1280 & 2 \\
Total & 2560 & 1 \\
& & 92
\end{tabular}


IgG EIA, in the population studied, has a positive predictive value of only $37 \%$. This is due to the low prevalence of syphilis and the large number of screening tests performed. Clearly, however, a positive EIA reaction must be confirmed by other treponemal tests. It is essential that laboratories that do not have confirmatory tests on site send EIA reactive sera to a reference laboratory for confirmation.

The incidence of positive tests with the EIA that are unconfirmed $(1.4 \%)$ is comparable to that with using VDRL and TPHA as screening tests $(1 \cdot 6 \%)^{3}$

Our results indicate that false positive EIA reactions are commoner in an STD population when compared with antenatal women but are not associated with any individual STD. The lower incidence of genital warts in patients with false positive tests compared with the control clinic population is difficult to explain. Warts are controlled mainly via cell mediated immunity and humoral factors are thought to be relatively unimportant. ${ }^{7}$

There were fewer women in the false positive reactor group than the clinic population as a whole but this was not statistically significant. In this context it is interesting that the incidence of false positive IgG EIA results was lower in the group of pregnant women studied compared with the GUM population $(p<0.01)$. Since pregnant women are generally in more stable relationships than the GUM clinic population and are therefore less likely to have genital infections this may indicate that STDs do contribute to false positive reactions. Many other physiological changes in immunity and hormones also occur in pregnancy however and it is unclear as to the relative contribution of these different factors.

Women have a higher incidence of autoimmune diseases in general $^{8}$ but this may not be an important factor in determining a serological false positive reaction in this assay in view of the sex ratio observed in the false positive patients.

Rheumatoid factor, usually in the form of immunoglobulin $M$ (IgM) directed against host $\operatorname{IgG}$, is well recognised in syphilis and increases in incidence in the latter stages of the disease. ${ }^{9}$ The IgM-IgG complex may produce a false positive reaction by mimicking IgM specific antibody in EIA reactions. The absence of any false positive reactions would indicate that rheumatoid factor is not important in producing false positive reactions in the Captia Syph G EIA system, however. RF would also not appear to be a problem in the IgM EIA as evidenced by the very low number of false positive IgM reactions.
It is also possible that false positive reactions may occur owing to the presence of heat shock proteins ${ }^{10}$ and endoflagella present in the sonicate of Treponema pallidum ${ }^{112}$

In conclusion, no individual sexually transmitted disease is associated with false positive reactions in the Captia Syph G EIA although false reactivity is commoner in an STD population than in pregnant women. This may suggest that the cause of these reactions is multifactorial or due to a different mechanism. Despite a low positive predictive value the test is comparable to traditional screening methods with regard to sensitivity and specificity but is potentially cheaper when large numbers of samples are processed, particularly by automated systems.

Address for correspondence: Dr JDC Ross, Department of Genitourinary Medicine, Edinburgh Royal Infirmary, Lauriston Place, Edinburgh EH3 9YW.

1 Young H, Moyes A, McMillan A, Paterson J. Enzymeimmunoassay for anti-treponemal IgG: a screening or a confirmatory test? J Clin Pathol (in press).

2 Lefevre J, Bertrand M, Bauriaud R. Evaluation of the Captia enzyme immunoassays for the detection of immunoglobulins $\mathrm{G}$ and $\mathrm{M}$ to Treponema Pallidum in syphilis. J Clin Microbiol 1990;28:1704-7.

3 Young H, Moyes A, McMillan A, Robertson DHH. Screening for treponemal infection by a new enzyme immunoassay. Genitourin Med 1989;65:72-78.

4 Hunter EF, Deacon WE, Meyer PE. An Improved FTA Test for Syphilis, the Absorbtion Procedure (FTA-ABS). Washington Public Health Report, 1964;79:410-2.

5 Rathlev J. Haemaglutination test utilising pathogenic Treponema pallidum for the sero-diagnosis of syphilis. $\mathrm{Br} J$ Venereal Dis 1967;43:181-5.

6 Young H, Penn C. Syphilis and related treponematoses. In: Smith GR, Easmon (eds). Topley and Wilsons Principles of Bacteriology, Virology and Immunity (8th ed), London: Edward Arnold 1990:587-604.

7 Robertson D, McMillan A, Young H (eds). Clinical Practice in Sexually Transmitted Diseases 2 nd ed, Churchill Livingstone, Edinburgh, 1989:354-5.

8 Kumar PJ, Clark ML (eds). Clinical Medicine, London: Balliere Tindall, $1987: 686$

9 Cerny EH, Farshy CE, Hunter EF, Larsen SA. Rheumatoid factor in syphilis. J Clin Microbiol 1985;22:89-94.

10 Hinderson P, Peterson CS, Pedersen NS, Hoiby N, Axelsen $\mathrm{NH}$. Immunological cross-reaction between antigen $\mathrm{Tp}-4$ of Treponema pallidum and an antigen common to a wide range of bacteria. Acta Path Microbiol Scand 1984;92:183-8.

11 Coleman JL, Benach JL. Identification and characterisation of an endoflagellar antigen of Borrelia burgdoreri. J Clin Invest 1989;84:322-30.

12 Luft BJ, Jiang W, Munoz P, Dattwyler RJ, Gorevic PD. Biochemical and immunological characterisation of the surface proteins of Borrelia burgdorferi. Infect Immun 1989; 57:3637-45.

Accepted for publication 5 August 1991. 